\title{
Liberales y conservadores de Nicaragua ¿falsos estereotipos?
}

Ma. del Carmen Collado $H$.

Al ser la disciplina que por excelencia busca en el pasado las explicaciones del presente, la historia está permeada por la subjetividad, los mitos y los estereotipos. La distancia temporal entre el enfrentamiento liberal-conservador y el presente no ha sido suficiente para abandonar los esquemas creados al respecto y lograr mayor objetividad en el análisis del proceso. La pugna entre liberales y conservadores, tan importante en la construcción de las naciones independientes latinoamericanas, no ha podido ser totalmente desmitificada. Marcados por la historia oficial y su maniqueísmo, se han creado estereotipos alejados de la realidad, que niegan la incorporación de la experiencia conservadora como parte de nuestra historia.

Profundamente impregnados por la concepción iluminista del progreso, se ha asociado a éste con el liberalismo y, como contrapartída, se ha identificado al conservatismo con lo reaccionario y, por ende, lo que no pudo ser. Además, la participación política de los conservadores al lado de las intervenciones extranjeras y los gobiernos espurios han provocado que los historiadores, salvo algunas excepciones, manifiesten poco interés por su estudio, o no los analicen en su real dimensión, despojándolos del sambenito de traidores. En cambio, los liberales han sido presentados como progresistas, republicanos, igualitarios y este velo ha cubierto contradicciones tales como las formas dictatoriales que asumieron históricamente, o la explotación que los indígenas y campesinos padecieron bajo la bandera del liberalismo.

Al iniciarse la vida independiente en los países hispanoamericanos, los sectores sociales dominantes y el reducido segmento medio de comerciantes, agricultores y profesionistas se escindieron en dos grandes agrupaciones políticas: liberales y conservadores. En algunos casos esta división respondía a proyectos políticos y económicos opuestos, pero en otros eran simples enfrentamientos de tipo personalista o caudillesco por el control del aparato político. Al margen de los orígenes del choque entre ambos grupos, lo cierto es que sus pugnas llenaron, casi sin excepción, buena parte del siglo xIx, condujeron a la anarquía e incluso provocaron intervenciones extranjeras. Centroamérica no escapó a esta realidad; la lucha entre liberales y conservadores alcanzó gran algidez en Guatemala, El Salvador, Nicaragua y Honduras y tuvo un impacto mucho menor en Costa Rica. Sin embargo, es imposible generalizar sobre las implicaciones sociopolíticas de estos movimientos en cada uno de los países del área, debido a que la propia estructura social fue la causante de las diferencias presentadas al aplicar el llamado modelo liberal o conservador.

Este artículo se propone explicar las características del liberalismo y el conservatismo en la historia independiente de Nicaragua y reflexionar sobre las grandes similitudes y las diferencias entre ambos bandos. Al confrontar la realidad nicaragüense se desvanecen las afirmaciones de algunos especialistas centroamericanos en el sentido de 
que las reformas liberales fueron tardías e incompletas en este pais. ${ }^{1}$ No sólo se encuentran grandes convergencias en los planteamientos político-económicos de los llamados liberales y conservadores, sino que las reformas emprendidas por los gobernantes del periodo conservador de los Treinta Años responden a lo que se ha considerado parte del ideario liberal. Con base en datos obtenidos en las ćonstituciones vigentes durante el siglo pasado, pero sobre todo en fuentes secundarias, se aprecia la manera en que el entorno político, económico y social determinó el accionar de liberales y conservadores en el ejercicio político entre 1821 y 1909. El material disponible impide profundizar en el análisis doctrinario del liberalismo nicaragüense; en cambio, permite abundar en los intereses derivados de la pertenencia de clase, las fidelidades de tipo patriarcal y las alianzas políticas que de ellas nacieron.

De manera muy esquemática se ha señalado que en América Latina los liberales eran republicanos, federalistas, proclives al predominio del parlamentarismo, anticlericales y defensores del libre cambio. Los conservadores eran monárquicos, en algunos casos, o partidarios de un modelo republicano de ejecutivo fuerte; centralistas, defensores de los privilegios eclesiásticos y proteccionistas en el plano económico. Con el transcurso del tiempo las formas de participación política también entraron en el terreno de las pugnas libero-conservadoras; así, mientras los primeros no imponían cortapisas para el acceso a los puestos de elección popular, los segundos pugnaban por limitarlo a las clases propietarias. Desde luego, algunas de las generalizaciones expuestas pierden validez en el momento de confrontarlas con el contexto nicaragüense y como se verá, en muchos aspectos parece borrarse la frontera entre unos y otros grupos políticos.

Como es sabido, al momento de declararse la independencia en 1821, Nicaragua formaba parte del Reino de Guatemala junto con los hoy países de Guatemala, El Salvador, Honduras y Costa Rica y el estado mexicano de Chiapas. La transición a la autonomía fue pacífica, porque las propias autoridades coloniales tomaron la iniciativa ante el caos político reinante en la metrópoli, y con el fin de evitar revueltas populares. Pero la noticia de la independencia de Guatemala, aunada a la de la independencia mexicana en forma de monarquía constitucional, contenida en el Plan de Iguala, sembraron la división en Centroamérica. Cada ciudad importante, por medio de su cabildo, resolvió a su arbitrio la aceptación del Acta de Independencia de Guatemala o la adhesión al Imperio mexicano proclamado por Iturbide. Este proceso centrífugo surgido de las profundas rivalidades económico-políticas existentes entre Santiago de Guatemala y las capitales y ciudades provinciales, también tenía su origen en la desintegración económica y geográfica que caracterizaba a la Centroamérica de aquellos años. De manera que la primera gran escisión política surgió en 1821, cuando León se adhirió al Imperio, secundando a Guatemala, en contraste con Granada que apoyó la fórmula republicana. Surgieron entonces las dos agrupaciones políticas cuya división

' $C f$. Edelberto Torres Rivas, Centroamérica hoy, México, Siglo XXI Editores, 1976, p. 22-24. Héctor Pérez Brignoli, Breve historia de Centroamérica, México, Alianza Editorial, 1986, p. 78-79. Ciro F.S. Cardoso y Héctor Pérez Brignoli, Centroamérica $y$ la cconomia occidental (1520-1930). San José, Editorial Universitaria de Costa Rica, 1977, p. 303-304. 
era más clara y tajante en la antigua capital del reino, pero que a su vez se presentaban más desleídas en las provincias. Los conservadores o serviles apoyaron la monarquía con tal de resguardar los privilegios del clero y de las clases propietarias, en tanto que los liberales o fiebres apoyaron la fórmula republicana y clamaron por la soberanía popular.

Fue a partir de la primera guerra civil de Nicaragua en 1824 cuando se identificó con mayor claridad el embrión de los futuros partidos liberal y conservador. El primero, acaudillado por Cleto Ordóñez, contaba con el apóyo de los pequeños hacendados de Granada, algunos profesionistas y la gente pobre de los barrios de esta ciudad; pugnaba por un gobierno civil, producto de elecciones populares y apoyaba el proyecto republicano federalista al igual que sus correligionarios guatemaltecos. Los conservadores, encabezados por Sacasa -miembro de la familia de comerciantes más rica-, contaban con el respaldo de los grandes hacendados comerciantes de Granada, los hacendados, el alto clero de León y también fue secundado por el pueblo de los barrios. La facción conservadora, por sus intereses, estaba por un gobierno que si bien podía tener la forma republicana, debía ser centralista y garantizar sus privilegios de clase y los del clero y, sobre todas las cosas, asegurar la libertad de comercio y quedar subordinado a los intereses económicos de las grandes familias. ${ }^{2}$ Indudablemente este enfrentamiento entre fiebres y serviles era paralelo al que se vivía en Guatemala, pues a partir de la declaratoria de independencia total y absoluta de Centroamérica, dada después de la caida del imperio de Iturbide, el antagonismo entre ambos grupos se forta- ${ }^{\prime}$ leció en el seno del Congreso.

Ante la inexistencia de programas políticos que consideraran cambios favorables a los sectores mayoritarios de la población, la adhesión de los peones, los pequeños agricultores y los artesanos a una $u$ otra facción casi nunca se explica por convicciones políticas, sino por simples lazos de tipo clientelista que se entretejieron entre ellos y las clases dominantes como resultado de la estructura económica colonial, o bien por el magnetismo que irradiaba algún caudillo entre las masas o por la simple posibilidad del pillaje. En general el pueblo, sobre todo el urbano, apoyaba a los liberales por su animadversión a los grandes propietarios, a los comerciantes y al alto clero. No es posible, sin embargo, definir de manera inequívoca la lealtad política de los grupos subalternos en términos de intereses sociales, pues muchas veces lo que estaba en juego era el dominio de una ciudad sobre otra, o más aún las ambiciones de alguna familia de controlar el poder. ${ }^{3}$ Asi no siempre resulta acertado descubrir en las pugnas de León y Granada el enfrentamiento entre el proyecto liberal o el conservador. Entre la entonces denominada facción liberal existia un claro antagonismo con los grandes propietarios y comerciantes, nacido de que actuaban como una seudoaristocracia que se veía a si misma como la única capaz de gobernar al país; en este sentido aquélla representaba los intereses populares entendidos como la posibilidad de ampliar la participación política.

\footnotetext{
2 José Coronel Urtecho, Reflexiones sobre la historia de Nicaragua; de Gainza a Somoza. La guerra cvil de 1824. León, Editorial Hospicio, 1962, vol. II.

${ }^{3}$ Cf. ibidem, p. 9 y José Dolores Gámez, Historia de Nicaragua, Managua, Banco de América, 1975, p. 386, 387 y 389.
} 
La lucha por la hegemonia política, el apoyo popular y la colonización de tierras de frontera que se desató en Nicaragua desde la independencia entre la oligarquía de León y de Granada tiene sus orígenes en el tipo de economía que privada en Nicaragua. Desde la etapa colonial, la entonces provincia había producido fundamentalmente para abastecer el mercado del reino; es decir que su más sustancial producción, el ganado, las carnes saladas, el cuero y los quesos se consumían en el área. Por tanto su vinculación con el mercado mundial a través de productos como el añil fue relativamente de menor importancia. Las pésimas comunicaciones trajeron como consecuencia un gran aislamiento regional de la provincia e hicieron posible que surgieran dos ciudades económicamente autónomas cuya influencia se extendió a las zonas circundantes. Así León, la capital provincial, representaba los intereses de la oligarquía ganadera y.productora de cereales, en tanto que en Granada se asentaban los hacendados añileros y los grandes comerciantes. La riqueza e importancia de Granada contrastaban con el menor desarrollo de León y alimentó los deseos de la oligarquía granadina porque su ciudad se convirtiera en la capital de Nicaragua.

Al erigirse Nicaragua como Estado libre en 1838, ante el fracaso del proyecto federal, se agudizó la lucha entre las dos grandes oligarquías locales por la preeminencia política y ello condujo a un prolongado periodo de anarquía que culminó con la invasión filibustera de William Walker en 1855. No obstante, durante esta etapa la lucha entre León y Granada adquirió un contenido ideológico más claro. Mientras León se convirtió en la abanderada del liberalismo, Granada hacía lo propio con el conservatismo. El continuo enfrentamiento entre ambas localidades ocasionó una constante mudanza de la capital entre León y Granada y a la larga acarreó el establecimiento definitivo de la capital en Managua.

En 1838 entró en vigor en Nicaragua la primera constitución que declaraba al país libre y soberano. Por influencia liberal se adoptó el régimen republicano, con un ejecutivo encabezado por un director que duraba dos años en su cargo y una legislatura bicameral. El Estado se declaró protector de la religión católica, pero admitía la existencia de otros credos religiosos. Las elecciones eran indirectas, votándose primero para los electores de las juntas populares, para de ahí nombrar a los electores de las juntas de distrito. También incluía un capítulo dedicado a las garantías individuales de todos los habitantes. La calidad de ciudadano se otorgaba a los varones mayores de 20 años o a los mayores de 18 años casados o con algún grado académico; exigía además que los ciudadanos tuvieran alguna profesión u oficio. ${ }^{4}$ En términos generales esta constitución se caracterizó por el vigor otorgado al poder legislativo en contraposición con la debilidad del ejecutivo.

La tendencia liberal de esta carta magna refleja las visiones políticas de la fracción leonesa, dirigida por elementos del naciente sectò medio fundamentalmente universitarios, y por los hacendados y pequeños comerciantes de esta localidad. De acuerdo con las concepciones políticas de los liberales o "calandracas" (nombre de un insecto que devora las gramíneas), el Estado era el depositario de la sobera-

4 Cf. Emilio Alvarez Lejarza, Las constituciones de Nicaragua (Exposición, críkica y textos), Madrid, Ediciones de Cultura Hispánica, 1958, p. 425-431. 
nía popular y al poder ejecutivo debia contraponerse un fuerte parlamentarismo. ${ }^{5}$ En 1847 se estableció una logia masónica en León y el liberalismo tomó nuevo impulso, luchando por libertad e igualdad mayores, influido probablemente por los movimientos libertarios europeos de 1830 y 1848 . En parte como resultado de sus inquietudes, se propusieron reformas a la constitución para garantizarlas a los ciudadanos, limitar el poder militar y restringir más las facultades del ejecutivo. Pero dichas reformas propuestas en 1848 , no entraron en vigor porque no hubo quórum.

Por su parte, los conservadores o "timbucos" (nombre que hace alusión a la obesidad de las clases altas), con el apoyo de los grandes comerciantes y hacendados granadinos favorecidos por la estructura económica colonial que se conservó hasta 1870 , tenian una concepción elitista del Estado en la cual los propietarios debían ser el principal elemento. Deseaban limitar las libertades ciudadanas, restringir el voto, el derecho a ocupar cargos de elección popular a los propietarios y establecer un ejecutivo fuerte. Pedro Francisco de la Rocha, ministro de Hacienda del director Laureano Pineda, en su Revista Política explica el contenido de ambas posiciones, con las siguientes frases:

Los demagogos aún proclaman con toda energía revolucionaria la teoría más exagerada de los principios democráticos, una administración descansando meramente sobre dos polos: libertad extrema, igualdad absoluta: invocan la libertad de prensa que, cual la lanza de Aquiles, curaría los males que ha causado: la libertad de voto sin sisa ni escatima, sin ninguna condición de propiedad, ni de ilustración, así de electores para ser admitidos en las .Asambleas primarias electorales, como las de los elegibles para ser colocados en los empleos [...] abandonando a la clase más numerosa y menos ilustrada el proceso y principal acto del sistema electoral... La simultánea cooperación del propietario y del hombre ilustrado estrecha los vínculos políticos y mantiene la Unidad del Estado. La civilización ilumina y la propiedad conserva; y ambos caminan mano a mano en las vías de la cultura y el progreso $[\ldots]_{6}$

Por otro lado, las divergencias en el pensamiento económico de liberales y conservadores guatemaltecos no corresponden a la realidad nicaragüense. De acuerdo con Ralph Lee Woodward, los liberales eran seguidores de Smith, Ricardo y Malthus, mientras que los conservadores eran adeptos de los fisiócratas, cuyas teorías, en tanto que otorgaban a la riqueza agrícola el papel principal dentro de la economía, les servian para justificar el latifundismo. ${ }^{7}$ Sin embargo, en Nicaragua la tendencia general de ambos partidos era hacia el libre cambio, seguramente debido a la creencia en el destino de comunica-

sJorge Eduardo Arellano. "El primer historiador de Nicaragua" en Revista Conservadora del Pensamiento Centroamericano, núm. 180, Managua, julio-septiembre de 1983 , p. $10-11$.

${ }^{6}$ Pedro Francisco de la Rodea, "Revista política sobre la historia de la Revolución de Nicaragua en defensa del exdirector don José León Sandoval" en Revista Conservadora del Pensamiento Centroamericano, núm. 180, Managua, julio-septiembre de 1983, p. 33 y 73 .

${ }^{7}$ Ralph Lee Woodward, Privilegio de clase y desarrollo económico. Guatemala 17031871, San José EDUCA, 1981, p. 187. 
ción interoceánica que entonces se creía firmemente Nicaragua debía cumplir.

En 1853 el ascenso al poder ejecutivo de Fruto Chamorro, miembro de una de las familias conservadoras granadinas más destacadas, inclinó la balanza del lado del conservatismo. En 1854 se reformó la constitución limitando las garantías individuales - por ejemplo fue eliminada la inviolabilidad del domicilio, la igualdad de todos los ciudadanos para ocupar cargos públicos, las aprehensiones injústificadas, los sirvientes perdieron la calidad de ciudadanos-. Para adquirir la categoría de ciudadano era necesario además de ser mayor de 21 años, o de 18 años los casados o con estudios universitarios, un capital de 300 pesos o un oficio o trabajo que proporcionara ingresos mayores al tope establecido. El gobierno se declaró protector de la religión católica. El voto siguió siendo indirecto a través de juntas electorales de cantón y de distrito. Por último, otro de los aspectos notables contenidos en este cuerpo de leyes fue la ampliación de las facultades ejecutivas en detrimento de las legislativas y la extensión del periodo presidencial a cuatro años. ${ }^{8}$

La puesta en vigor de esta constitución, que evidentemente respondía a los proyectos conservadores, desató la firme oposición del grupo liberal y una nueva y más encarnizada guerra civil. Así como Fruto Chamorro era la cabeza visible de los conservadores o legitimistas, Máximo Jerez lo era de los liberales o democráticos. En su decisión de llegar hasta las últimas consecuencias en este nuevo enfrentamiento, los democráticos cayeron en el error de contratar a filibusteros norteamericanos para que pelearan a su lado. Así llegó el famoso aventurero William Walker, quien antes de incursionar en Nicaragua había organizado previamente dos invasiones a México, una a Sonora y otra a Baja California, con el fracasado objeto de establecer una república independiente en estos territorios. Los liberales ignoraban que Walker tenía su propio proyecto político: establecer una república esclavista del trópico que más adelante incorporara al resto de Centroamérica. En 1857 las fuerzas coaligadas de los otros países del área, unidas a las de Nicaragua, lograron la expulsión de Walker, quien para entonces, gracias a sus argucias, había obtenido la silla presidencial.

Como resultado de la invasión extranjera, los democráticos cayeron en el descrédito y por un largo periodo el poder quedó en manos de los intereses conservadores de la oligarquía granadina. Entre 1858 y 1888 imperó un régimen conservador en el que los más prominentes miembros de la elite de Granada ocuparon el poder ejecutivo. Mediante un pacto con la oligarquía leonesa a la que se le otorgaron puestos en el legislativo, los conservadores pudieron alternar pacíficamente en el poder e implantar su propio proyecto. Esta etapa coincidió con un aumento en la demanda internacional del añil que favoreció a los hacendados comerciantes granadinos. Durante sus primeros años este régimen recibió el respaldo de los conservadores guatemaltecos que con Carrera detentaban el poder desde finales de la década de los treinta. En el terreno económico y político fueron múltiples los logros de este primer periodo prolongado de paz. El añil y el ganado se exportaron con buenos rendimientos, se colonizaron tierras de frontera, se establecieron las primeras líneas telegráficas y ferroviarias y se

${ }^{8}$ Álvarez Lejarza. op. cit. p. 505-530. 
inició comercialmente el cultivo del café. En el plano político, lo más importante fue el surgimiento de un Estado nacional de corte oligárquico, cuyo nacimiento puede explicarse como una reacción nacionalista ante la intervención extranjera, anterior a la integración económica y geográfica del territorio y a la vinculación preponderante de la producción cafetalera con el mercado mundial.

En 1858 entró en vigor una nueva constitución, que conservó buena parte del espiritu de la de 1854, aunque afinó algunos puntos. Amplió las garantías individuales, también fue mucho más específica en lo referente a las causas de pérdida de la ciudadanía, continuó con el sistema de elecciones indirectas por medio de juntas populares, de distrito y de departamento para la elección de senadores. El carácter elitista del poder de los conservadores se trasluce en las limitaciones impuestas para los puestos de elección popular. Así, para ser presidente se exigía, entre otras cosas, tener un capital mayor a 4000 pesos en bienes raíces; para ser senador se requería un capital fundiario de 2000 pesos y para ser ciudadano rentas mayores a 100 pesos. Desde luego, se trataba de una participación política excluyente que favorecía únicamente a los grandes y medianos propietarios.

A partir del ascenso de Fruto Chamorro a la presidencia, el grupo conservador se fortaleció mediante la promoción de clubes políticos que se convirtieron en el núcleo del partido. En la administración de Tomás Martínez los conservadores se separaron en cuatro tendencias. La primera aglomeró a la mayor parte de los conservadores; se consideraban seculares y progresistas, pero buscaban cambios graduales para evitar alteraciones en el orden social. La segunda, llamada de los "genuinos", quería mantener a toda costa las ligas entre la Iglesia y el Estado. Los jóvenes formaron un tercer grupo que se alió indistintamente con las dos primeras. Por último, surgió el segmento jacobino que más adelante se uniría al partido liberal. Es notable el agnosticismo predicado por la mayor parte de los conservadores en este periodo. Desde finales de la década de los sesenta, los conservadores intentaron reformar al conservatismo, lo cual se manifestó en sus tendencias a limitar la influencia clerical a los aspectos religiosos. Según Emilio Álvarez Lejarza, los cambios introducidos precipitaron a los conservadores hacia el liberalismo, a consecuencia de la falta de instrucción religiosa imperante en Nicaragua desde las reformas liberales de Morazán. También afirma que existía un prejuicio entre la clase dominante que los llevaba a identificar a los creyentes como gente inculta e ignorante. ${ }^{9}$ No obstante, estos argumentos son insuficientes para explicar la transformación de los conservadores.

Durante los Treinta Años se anuló la obligación civil de pagar el diezmo, se declaró libre la observancia del domingo, se fijaron montos para el pago de servicios religiosos y de primicias, la educación se hizo libre, restringiendo la influencia clerical, y se ordenó la expulsión de los jesuitas. A pesar de la oposición del obispo, la Iglesia fue forzada a vender algunas de sus tierras incultas o sobre las que no tenía títulos de propiedad. ${ }^{10}$

\footnotetext{
"Emilio Álvarez Lejarza, "El liberalismo en los 30 Años" en Revista Conservadora del Pensamiento Centroamericano. núm. 51. octubre-diciembre de 1964, Managua, p. 23-24.

${ }^{10}$ Benjamin Teplitz, The Political and Economical Foundations of Modernization in Nicaragua. The Administration of José Santos Zelaya, 1893-1909, tesis doctoral de Howard University. Ann Arbor, University Microfilms International, 1974, p. 77.
} 
En agosto de 1873 Nicaragua firmó un tratado con Guatemala y El Salvador, al que más tarde se unió Honduras, en el cual los gobiernos se comprometían a colaborar en la consolidación del liberalismo. Desde 1871 el movimiento liberal triunfó en Guatemala y comenzó a predominar la figura de Justo Rufino Barrios quien implantó una politica abiertamente anticlerical y trató de influir en el resto de la región. La adhesión de Nicaragua a este pacto no es gratuita y se explica en parte tanto por las presiones de Guatemala cuanto por los afanes de los principales conservadores por revitalizar el conservatismo.

Durante el gobierno de Zavala se contrató a varios profesores masones españoles para hacerse cargo del Colegio de Granada y del Instituto de León; debido a la influencia de estos maestros, las escuelas se convirtieron en verdaderos semilleros del liberalismo. En 1881 fue ordenada la expulsión de los jesuitas de territorio nicaragüense con el pretexto de que habían apoyado y participado en los importantes levantamientos indígenas de ese año. Desde 1874 el presidente Cuadra había estado manifestando que cada día aumentaban más las presiones de Guatemala y El Salvador para que aquéllos fueran sacados de territorio centroamericano y que incluso se temía una invasión. A fin de evitar un enfrentamiento con la Iglesia, el gobierno de Zavala había pedido a Fernando Chamorro que gestionara en Roma el retiro de la Compañía de Jesús, así como la aprobación papal para la desamortización de ciertos bienes eclesiásticos; como era lógico esperar, el Papa se negó a aprobar las peticiones.

En general, en América Latina la tendencia anticlerical era parte sustancial del ideario liberal, pero en Nicaragua se observó en los gobiernos conservadores. Cabe entonces pensar que la desviación del programa conservador hacia el anticlericalismo debió proceder de las condiciones imperantes en Nicaragua. Si como hemos visto fue precisamente durante este periodo cuando surgió el Estado nacional, resulta lógico que los dirigentes buscaran el sometimiento del clero y la limitación de su poder político y económico, pues era contradictoria la convivencia de un Estado con una Iglesia poderosa. Por ello en la Constitución de 1858 se impusieron las primeras restricciones a la propiedad que prohibieron las vinculaciones y los destinos venales, pero como hemos visto se avanzó poco en la desamortización de los bienes eclesiásticos. Acompañando al proceso de consolidación estatal, el relativo crecimiento de la economía mediante la exportación de ganado y añil que se experimentó en estos años, aunado a la expansión del cultivo del café para exportación, necesariamente demandaban innovaciones como el tendido de vías férreas y líneas telegráficas, la apertura de tierras antes baldias al cultivo y la generalización del trabajo forzoso. Pero el aumento de la demanda del comercio exterior no explica por sí solo el crecimiento de las actividades agrícolas y el progreso de las comunicaciones. Si éstos fueron posibles era porque existía un Estado promotor de la agricultura.

Así como en el plano del enfrentamiento entre la Iglesia y el Estado se da la contradicción de que sean los propios conservadores los que impulsan la reforma, en el plano económico se da la contradicción de que aunque querían preservar el predominio del sector hacendado y comercial tradicional, apoyaron el desarrollo del café que a la larga ocasionó el ascenso socioeconómico de un nuevo sector mestizo de caficultores que no tenían aún representación en el aparato estatal. 
Desde el punto de vista de la agricultura, se abrieron terrenos baldíos al libre denuncio, que fueron adjudicados a medianos y sobre todo grandes propietarios, con base en numerosas leyes de tierras baldias que fueron proclamadas. En cuanto a los aspectos laborales, la carencia de mano de obra siguió siendo un problema serio en la economía. En su afán de terminar con este inconveniente, los conservadores dictaron leyes que obligaban a los campesinos a cumplir con sus contratos y a pagar sus deudas de trabajo. En 1862 se crearon por primera vez los jueces de agricultura, encargados de vigilar que los campesinos quedaran sujetos al trabajo por medio de su contrato. Las sucesivas leyes dadas en este sentido recrudecieron el trabajo forzoso y con ello se fortalecieron las formas precapitalistas de trabajo. ${ }^{11}$ Acompañando a estas medidas los conservadores optaron por la invasión de tierras comunales y también por la prohibición a los comuneros de que vendieran sus productos con fines comerciales a fin de separar al campesino de los medios de producción y asegurar un crecimiento de la mano de obra. En 1877 se dictó una ley que obligaba a la desaparición de los ejidos, estableciendo la división individual de las tierras entre los usufructuarios y forzándolos a vender las tierras no cultivadas; sin embargo esta ley no se aplicó y en la medida que se les permitió, los ejidatarios siguieron explotando tradicionalmente sus posesiones. ${ }^{12} \mathrm{El}$ aumento de las invasiones a las tierras comunales, así como la compulsión para que los indígenas trabajaran gratuitamente en la construcción de caminos, líneas telegráficas o para que se engancharan en las fincas ocasionó importantes levantamientos indigenas en 1881 .

La expansión del cultivo de café, que hacia finales de la década de los ochenta, se convirtió en el principal producto de exportación, exigía transformaciones profundas en la estructura de comercialización, financiamiento, mano de obra y apertura de más tierras al cultivo que los conservadores no podían satisfacer por sus vínculos con la economía tradicional. Estos factores, unidos a la crisis del pacto interoligárquico, causaron levantamientos e hicieron posible el ascenso político del partido liberal que contaba con el respaldo del sector caficultor emergente. De tal suerte que en 1893 José Santos Zelaya asumió el poder desplazando de la administración por 16 años al grupo conservador.

El mismo año en que Zelaya tomó bajo su cargo el ejecutivo, fue aprobada una nueva constitución, llamada la "libérrima", por un Congreso Constituyente conformado mayoritariamente por liberales radicales. En ella se estableció el voto directo universal y secreto, se abolió la pena de muerte, introdujo el hábeas corpus, prohibió la reelección, instauró un congreso unicameral, restableció la vicepresidencia, limitó los fueros militares, otorgó amplias garantías individuales y aumentó las facultades municipales. También garantizó la libertad de educación y dispuso que la primaria sería gratuita y obligatoria haciendo laica la impartida por el Estado. Uno de sus aspec-

"José Salomón Delgado, "Unidades de producción más importantes durante el periodo de los 30 años conservadores (hacienda tradicional y la mano de obra)" en Anuario de Estudios Centroamericanos, núm. 1, 1974, San José, Universidad de Costa Rica, p. 162.

12 Francisco Pérez Estrada, "Breve historia de la tenencia de la tierra en Nicaragua" en Revista Conservadora del Pensamiento Centroamericano, núm. 51 , octubre-diciembre de 1964. Managua. p. 132. 
tos más destacados fue el anticlericalismo que permeó la nueva carta magna. Aseguró la separación total y definitiva de la Iglesia y el Estado, abolió lós diezmos y primicias, estableció el matrimonio civil y el divorcio, secularizó los cementerios, dio igualdad a todas las religiones y prohibió los bienes de manos muertas.

Estas reformas representaban los proyectos del grupo liberál en áscenso, apoyado por los cafetaleros y que con un programa político revolucionario intentaba consolidar a un Estado que difería del conservador. Lo cierto es que la mayor parte de aquéllas quedaron únicamente en el papel y resultaron inaplicables a las condiciones de analfabetismo, miseria y aislamiento de la mayor parte de la población. Por más que de jure se dieron multitud de derechos ciudadanos y el sufragio directo universal masculino, en la práctica fueron pocos los cambios que esta nueva situación trajo, sobre todo si pensamos en los indigenas y campesinos. Por otro lado, José Santos Zelaya gobernó durante la mayor parte de su régimen con facultades extraordinarias o bajo estado de sitio. Así el Congreso, que en teoría tenía amplios poderes, fue reducido a la impotencia. Pronto fue eliminado el obstáculo legal que impedía la reelección de Zelaya, quien se mantuvo en el poder hasta 1909 , fecha en la que una revuelta organizada por caudillos conservadores y que contó con el apoyo de Estados Unidos lo obligó a renunciar. Se trató en esencia de una dictadura liberal durante la cual el Estado desplegó una gran participación en lo económico, merced a la cual se dio un progreso relativo.

El anticlericalismo fue una de las políticas más consistentes del régimen liberal y llegó a mayores proporciones que las logradas en el periodo conservador. Desde luego la oposición gubernamental a la Iglesia no llegó a alcanzar el radicalismo de la vivida en Guatemala o El Salvador; guardaba relación con el poder económico y político del clero en cada uno de estos países. En algunos periodos arreció el jacobinismo; por ejemplo, en 1905 se prohibió el uso del traje talar y los actos de culto religioso fuera de los templos; ello acrecentó las tensiones con la jerarquía eclesiástica y condujo a la expulsión del obispo Pereira y Castellón y de veinte clérigos. Los liberales aspiraban a lograr un entendimiento con el Papa en el cual el clero renunciara a su poder temporal, cediendo al Estado el terreno institucional que ocupaba; pero por el momento fue imposible para la Santa Sede aceptar las nuevas reglas del juego.

Otro aspecto relevante del zelayismo, que coincidió con las políticas establecidas por liberales de otras latitudes, como México y El Salvador, se refiere a la abolición de la propiedad comunal. En 1895 fueron despojados de sus tierras ejidales el cincuenta por ciento de los indigenas que habitaban el recientemente incorporado territorio de la Mosquitia. En 1906 se abolieron definitivamente los títulos sobre tierras comunales. La tendencia hacia la privatización de la propiedad que se observa a lo largo del siglo xIx era resultado de la expansión de las actividades agrícolas tanto en lo relativo al café, como a la explotación del caucho, las maderas preciosas y de tinte. Pero además de la necesidad de los finqueros que inducía a la expropiación de las tierras comunitarias y la de aumentar el flujo de mano de obra, existían argumentos ideológicos que hacían ver este tipo de propiedad como una forma obsoleta y atrasada, incompatible con el "progreso"; se pensaba además que la propiedad individual daría el carácter de ciudadano pleno al indígena. 
El régimen liberal zelayista representó de manera prioritaria los intereses del sector latifundista cafetalero que fue concentrando su poder alrededor de Managua. Durante este periodo el Estado intervino activamente en la economía y se lograron avances tales como el florecimiento de la minería, el establecimiento de algunas industrias, los ferrocarriles, los telégrafos, las líneas de vapores en el lago, la industria eléctrica o los teléfonos. En aras del progreso el gobierno otorgó una serie de concesiones para la explotación de recursos naturales, de importaciones de algunos bienes, de bancos, editoriales, etc. Se dieron subsidios a productores por medio de primas en los fletes, que beneficiaron por igual a toda la clase propietaria, independientemente del partido al que pertenecieran.

Las actividades agrícolas recibieron un impulso preferencial y se incorporaron al cultivo miles de hectáreas de tierras. Mediante sucesivas leyes, el Estado se convirtió en el principal vendedor de tierras calificadas como baldías. Al mismo tiempo la expoliación que sufrieron muchos campesinos provocó el aumento de mano de obra. Las leyes laborales complementaron esta política: obligaron al registro y al trabajo a toda la población mayor de 14 años. La introducción de credenciales, la ley contra la vagancia y la guardia civil dieron mayor control sobre la mano de obra, que quedó sujeta a las fincas fundamentalmente por el endeudamiento. Este conjunto de medidas puso de manifiesto la naturaleza explotadora del liberalismo que indudablemente contrasta con el relativo paternalismo que tradicionalmente había existido en las haciendas y que fue practicado por los conservadores. Sin embargo, cabe recordar que el recrudecimiento de las formas de trabajo forzosas así como la política confiscatoria de las tierras comunales se inició durante el periodo conservador.

La expansión cafetalera, al igual que la exportación de algunas materias primas agrícolas o minerales, introdujo formas capitalistas en Nicaragua sobre todo a partir del periodo liberal. Así el proceso de acumulación se basó en la expoliación de los campesinos, el sobreaprovechamiento de los recursos naturales y la explotación de la mano de obra por parte de la elite, al igual que en otros países en su fase de transición hacia el capitalismo.

Al parecer el proceso nicaragüense no pudo solucionar las contradicciones que él mismo generó. El grupo agroexportador nacional no logró formar una verdadera burguesía en tanto que conservó la propiedad latifundista y relaciones sociales de producción precapitalistas en el proceso de cultivo y cosecha del café. La renta del suelo y el predominio de formas no salariales en el campo impidieron el avance. Los factores económicos, el descontento político de la oligarquía conservadora por haber sido desplazada del sector hegemónico dentro del bloque del poder, aunados a la impopularidad del régimen que provocó la inflación, llevaron a la guerra civil y al desgajamiento del Estado a partir de la caída de Zelaya. Posteriormente la ocupación norteamericana, aliada con los intereses conservadores y la caída de los precios del café, frenaron las transformaciones económico-sociales.

Vistos en perspectiva, existen diferencias entre liberales y conservadores, principalmente por cuanto a formas de participación política se refiere. Los primeros pugnaban por la igualdad y la soberanía popular en tanto que los conservadores tenían una concepción elitista del Estado, pero la historia demuestra que la intervención del pueblo en el gobierno fue sólo una quimera no llevada a la práctica durante 
las administraciones liberales. Desde el ángulo de las leyes, hay grandes disparidades, pero éstas se difuminan en el momento de analizar su aplicación práctica. Si bien desde el punto jurídico existen grandes diferencias entre los regímenes en cuanto a las potestades del ejecutivo, en la práctica encontramos que mientras los conservadores las consignaron en el papel, los liberales las llevaron a la práctica pasando por encima de la constitución. El anticlericalismo fue más radical entre los liberales, pero inició sus primeros pasos durante el régimen conservador. El proyecto de desarrollo agroexportador liberal, sin duda fue mucho más claro y ello se explica por la vinculación del segmento cafetalista con el zelayismo. Entre los países centroamericanos llama la atención el profundo sentido elitista que ha tenido el poder; si bien se han vestido con los ropajes de constituciones liberales copiadas de otros países, fundamentalmente de los Estados Unidos, dichas leyes no correspondian a su nivel de desarollo. Así la democracia ha sido más una ficción que una realidad. El poder ha sido controlado por un pequeñísimo sector de la población - a lo más que llegó durante el siglo pasado fue a incorporar al reducido sector medio urbano, o a los artesanos. La participación política reducida ha sido una realidad continua. También se trata de sociedades muy autoritarias y en las cuales el poder ha tenido un clarísimo contenido caudillesco o personalista. Así la institucionalización de la vida politica no se lagró durante el siglo pasado y es aún una meta por alcanzar. En todos los países, el triunfo del liberalismo vino acompañado necesariamente de la dictadura o "dictablanda" de uno u otro personaje. La manera como se consolidó en la realidad el liberalismo resulta indescifrable y chocante para quien intente compararla con la de los países democráticos occidentales. Los paralelismos, en cambio, resultan clarísimos si equiparamos a Centroamérica con cualquier otro país de América Latina o con algunos del Caribe.

Considerando los aspectos relevantes del liberalismo y el conservatismo en Nicaragua parece claro que el cisma no provino fundamentalmente de principios políticos, sino del enfrentamiento de familias o feudos personales por el control del poder. ${ }^{13}$ Probablemente era más claro y definido el proyecto de los liberales en cuanto a desarrollo económico se refiere, pero no se debe olvidar, como se señaló antes, que el impulso de la consolidación estatal que los conservadores generaron después de la expulsión de Walker, introdujo reformas que correspondian más bien al programa liberal. Estas reflexiones, producto de un primer acercamiento a la problemática política del siglo XIX nicaragüense, llevan a concluir que para desentrañar la naturaleza de los conflictos políticos durante el siglo pasado latinoamericano resulta indispensable estudiar los movimientos conservadores, o hacer una nueva lectura de los mismos, sobre todo si estamos conscientes de que al haber sido los conservadores los auténticos perdedores en esta lucha, su participación ha sido poco estudiada y quizá por lo mismo no los hemos incorporado cabalmente a nuestra historia.

${ }^{13}$ Teplitz, op. cit., p. 45 . 